\title{
Possible Reasons and Strategies for the "Threshold Phenomenon" in Free Active Vocabulary Acquisition: Evidence from Interviews with L2 Learners
}

\author{
Yinglai Yue ${ }^{1,2}$, Si Fan ${ }^{2}$, Zhuanping Hao' \\ ${ }^{1}$ Taiyuan Normal University \\ ${ }^{2}$ University of Tasmania
}

Keywords: free active vocabulary, threshold phenomenon, stagnation

\begin{abstract}
Free active vocabulary (FAV) is of great significance in second language (L2) learning. To some extent it determines the quality of speaking and writing. Meanwhile, FAV seems to be difficult to be acquired, and the FAV threshold phenomenon has been repeatedly detected in L2 learning. However, possible reasons and effective strategies for the threshold phenomenon were seldom explored. This study investigates students' consciousness on FAV development, teachers' guidance on FAV learning, the learning strategies students adopt (if any) to enlarge FAV storage, and the teaching strategies (if any) teachers adopt to assist students' FAV development. The aim of the study is to find factors in learning and teaching that may affect FAV development, and to find possible ways to facilitate FAV development.
\end{abstract}

\section{Research Motivation}

Free active vocabulary (FAV) refers to words that can be used voluntarily by people (Laufer \& Paribakht, 1998). FAV is significant in second language (L2) study, and to some extent, it determines the quality of speaking and writing (Astika, 1993; Coady, Magoto, Hubbard, Graney, \& Mokhtari, 1993; Engber, 1995; Laufer, 1994; Yamamoto, 2011). However, it seems that FAV is a difficult part in L2 learning, as even advanced English as a second language (ESL) learners' vocabulary use in speaking and writing tends to be limited. As early as 1991, Laufer has discovered that FAV tends to stop progressing after reaching a certain degree, no matter how much input is given to the learners. He called this phenomenon the "threshold phenomenon". After Laufer's (1991) research, the FAV threshold phenomenon was detected for numerous times (Gu \& Li, 2013; Huang, 2012; Lu, 2008; Tan, 2006; X. Wu \& Chen, 2000; Y. Zhao, 2011; Yue, 2018; Yue, 2019).

Although the existence of the "threshold phenomenon" has been confirmed repeatedly, the possible reasons for the stagnation of FAV, together with the possible effective strategies to promote FAV development, have seldom been explored. No interviews to L2 learners, as far as we know, have been conducted to investigate these issues from the L2 learners' point of view. Therefore, it is necessary to conduct relevant research. This study aims to find factors in learning and teaching that may affect FAV development, and to find possible ways to facilitate FAV development by interviews with L2 learners. The interview questions were designed surrounding 
students' consciousness on FAV development, teachers' guidance on FAV learning, the effective learning strategies students adopt (if any) to enlarge FAV storage, and the effective teaching strategies (if any) teachers adopt to assist students’ FAV development.

\section{Aspects of Interview Questions}

The interview questions were designed surrounding four aspects:

(1) Students' awareness of FAV in L2 study;

(2) Learning strategies (if any) adopted to improve FAV;

(3) Teachers' guidance on FAV learning; and

(4) Teaching strategies (if any) that may help promote students' FAV development.

\section{Research Method}

\subsection{Sampling and Participants of the Interview}

Three participants were involved in the interview, including one male and two females. The reason why no more interviewees were interviewed is that the pilot interview showed that the FAV learning and teaching seems to be at a primitive stage, as the information interviewees provided was limited and similar, and their reflection on the attention to FAV teaching and learning was relatively consistent. After three interviewees no new themes came out.

The interviewees were randomly selected from year-four English major students in a university in China. At the time of the interview, the interviewees were around 21 to 22 years old, and they were seniors in the second semester. They had completed all the courses required for the 4-year university study. The courses provided them with intensive English training in various perspectives, including reading, listening, speaking, English literature, linguistics and applied linguistics, western culture, etc. In addition, they had just completed a thesis writing of about 5,000 words, which was a compulsory requirement for graduation. The topics of the thesis were required to be related to L2 linguistics and applied linguistics, literature, translation, or culture. In addition, all of the three interviewees participated in the postgraduate entrance examination, in which English was one of the subjects.

\subsection{Instrument}

Table 1. Aspects and Corresponding Questions in the Interview

\begin{tabular}{|l|l|}
\hline \multicolumn{1}{|c|}{ Aspects } & \multicolumn{1}{c|}{ Corresponding questions } \\
\hline $\begin{array}{l}\text { Aspect One: Students' } \\
\text { consciousness of FAV in L2 study }\end{array}$ & $\begin{array}{l}\text { 1) Have you ever had difficulties in searching for suitable words to express the meaning you } \\
\text { want to express in L2 writing or speaking? } \\
\text { 2) What are the difficulties (if any)? } \\
\text { 3) Do you know free active vocabulary? Or do you know this type of vocabulary knowledge, } \\
\text { even if you do not know the terminology of it? } \\
\text { 4) Have you ever attempted to improve your free active vocabulary size in L2 study? }\end{array}$ \\
\hline $\begin{array}{l}\text { Aspect Two: Learning strategies } \\
\text { adopted to enlarge FAV }\end{array}$ & $\begin{array}{l}\text { 1) Have you ever taken some measures to enlarge FAV size? } \\
\text { 2) What are the measures (if any)? } \\
\text { 3) Do you think these measures are effective? }\end{array}$ \\
\hline $\begin{array}{l}\text { Aspect Three: Teachers' guidance } \\
\text { on FAV in L2 teaching }\end{array}$ & $\begin{array}{l}\text { 1) Have your teachers told you that FAV is important? } \\
\text { 2) Are there many teachers who did so? }\end{array}$ \\
\hline $\begin{array}{l}\text { Aspect Four: Teaching strategies } \\
\text { that may help students' FAV } \\
\text { development }\end{array}$ & $\begin{array}{l}\text { 1) Wo yout suggestions did they give you (if any)? } \\
\text { 2) What are they (if any)? }\end{array}$ \\
\hline
\end{tabular}

The instrument adopted in the study is a face-to-face interview. Based on the research aims and 
pilot study, questions in the interview are designed in four aspects, which are presented in Table 1. It should be noted that in the interview, extra questions may be added when necessary, so that more detailed information on the relevant topic can be obtained.

\subsection{Data Collection and Preparation}

Before the data collection, the student investigator asked the interviewees to answer interview questions as detailed as possible. They were also encouraged to raise questions if they had any doubts on the interview questions. Then the interview started. Each student was interviewed separately, so that their answers would not be affected by other interviewees. The entire process was recorded.

Interviews were audio recorded. Then the recordings were played and checked by the researchers to ensure that the interviewees answered the questions seriously. If details were given in the interviewees' answers, it was believed that the interviewees answered the questions seriously. It turned out that all the interviewees did the interview with a serious attitude, and therefore all the data were valid. Then the recordings were transcribed by the student investigator for further analysis. In order to protect privacy, the interviewees were kept anonymous, and they were coded as Interviewee A, Interviewee B, and Interviewee C.

\section{Results and Discussion}

Transcription of the recording consists of approximately 3,260 words in total. The student investigator read the transcription sentence by sentence, and then had the transcription encoded, arranged, and categorised. The interview results are reported and discussed in this section.

When being asked "have you ever felt difficulties in searching for suitable words to express the meaning you want to express in writing or speaking?”, the interviewees' answers were almost the same. They reported having difficulties in seeking for the right words to use in writing and speaking. Specifically, the students' challenge primarily lied in the fact that sometimes their effort in searching for the most accurate word failed. Interviewee A felt unsure sometimes about the precision of the candidate words in writing, or sometimes he could not find an exact word to express what he wanted to express. In this condition, he had to use a substitute instead. This led to the loss of accuracy in his writing. Interviewee B had the same concern. She said:

I definitely feel the difficulty. As a senior student, I start to have job interviews. In some of the interviews, the interviewers would require me to have oral communication (in English) with them. Sometimes I feel my vocabulary is rather limited... The word that I use is not precise, but I cannot find the precise one. (Interview B)

Interviewee $\mathrm{C}$ told the investigator that she suffered from this trouble frequently:

I think words have both general meaning and specific meaning, but in many cases I only know the general meaning. Thus, in a specific circumstance, I may not be able to find the specific word, and thereby have to use a general word to replace it.

The student then gave an example. Once she wanted to express "the 'American dream' contains different potential meanings in different times", but she could not find a suitable word to express "potential meaning", such as "connotation" or "implication". Thus she had to use the word "meaning" instead. She said this problem often occurred. Moreover, she told the investigator that the difficulty she faced was not in choosing the right word among options. The trouble seemed to be even worse: she could not think of optional words at all. She had to use a basic, general word, as it was the only one that could come into her mind. This difficulty corresponds with the statement by Swain (2000, p. 100): "Learners may notice that they do not know how to express precisely the meaning they wish to convey at the very moment of attempting to produce it...they notice, so to 
speak, a 'hole' in their interlanguage." This problem may result in the loss of important information the student wants to convey in writing and speaking. It can be inferred from the interview that the difficulty in FAV usage is common even among upper-intermediate to advanced students. These students' difficulty is primarily in retrieval, rather than in the selection of the right word among retrieved words.

The next set of questions is on students' consciousness of FAV in L2 study. All the interviewees indicated their awareness of FAV, and they all tried to enlarge FAV in their L2 learnig. Effective learning strategies in FAV development were then investigated. Interviewees reflected that taking deliberate "output" practice was helpful to them. For example, Interviewee A reflected that he tried to pay extra attention to the target word, and then forced himself to produce the word. When he encountered a new word in study, he would deliberately create chances to use the word in writing or speaking. Interviewee B stated a similar strategy. In reading, if some new words attracted her attention, the student would put them down in a notebook. If these words were encountered for a second time, she would pay more attention to it, and attempted to apply these words in writing. She said the purpose of this activity was to help these words be transferred from receptive to productive. The student stressed that if the word was not used, it would be forgotten with time passing by.

Analysing the context and putting down example sentences were deemed to play positive roles as well. Interviewee $C$ told the investigator that in reading, when she first encountered a new word that drew her notice, she would put down the word. If she encountered the word again, she would pay more attention to it, and considered why it was used in this context. By this method she would learn how to use the word. If she noticed that a word appeared frequently, she would look it up in a dictionary, and then copied the example sentences to her notebook. The reason to do this was because these examples might be helpful for her writing.

In the interview one phenomenon attracted the investigator's attention: the students seemed to be sensitive to word frequency in FAV acquisition. Two interviewees stated that usually if they only encountered the word once, they might notice it, but would not consider how to use it. Only when they met the word repeatedly would they try to output it by themselves. This tendency may imply that word frequency is considered to be important by students. If a word appears frequently, they will think that the word is worthwhile to be transferred into FAV; if a word does not appear frequently, they tend not to think so, and thereby will not make efforts to develop it into FAV. This finding indicates that words are usually acquired in order. More frequently used words are usually learned before less frequently used ones (Schmitt et al., 2001). The suggestion is that repeated occurrence of the target words may be helpful for FAV development. In texts or lectures, teachers are advised to deliberately increase the occurrences of the target word, so that students' attention can be attracted. This measure may have an indirect positive effect on FAV development.

The interviewees described some other strategies that they felt effective as well. One strategy was collecting synonyms. Interviewee $C$ introduced this method, and she thought it was very helpful to her. She said at lower proficiency level, words encountered were mostly basic words. With further study, more synonyms were encountered in intensive and extensive reading. The interviewee deemed that collecting synonyms was helpful to writing. In this way various words could be used, therefore the writing would not be as plain as water. The student pointed out that if only the most basic words were applied, quality of the writing would be similar to that of middle school students.

Another strategy being reported was to make use of “context”. Interviewee A told the student investigator that he often looked for authentic reading materials, such as those in foreign English magazines. If he encountered a new word in these reading materials, he would try to figure out the meaning of the word in the context. Then he would know that it was appropriate to use the word in 
this type of context. When he met a similar circumstance, he would know that it was proper to use this word in it. The interviewee reported that this learning strategy worked for him.

The Output Hypothesis by Swain $(1985,1995)$ can be used to explain why this strategy is effective. The Output Hypothesis states that although comprehensible input is essential in second language acquisition, solely having input is not enough. Comprehensible output is essential as well. The hypothesis holds that language production, no matter in spoken form or written form, would elicit language learning/acquisition to occur (Swain, 1985). According to Swain (1985), being "pushed" not only means to make learners convey a message, but also to convey it precisely, coherently, and appropriately. He believes that the act of "pushing" would force ESL learners to make more mental effort in study, thus process the language more deeply. Swain's (1985) Output Hypothesis is originally on general second language acquisition, rather than specifically on vocabulary or FAV acquisition. However, some scholars found this theory was relevant to L2 FAV learning as well, and therefore they applied this theory to L2 FAV study. For instance, Laufer (1998) holds that if L2 learners are not pushed to use L2 words, the words may never be activated, and they may only remain in passive vocabulary. Henriksen (1999) believes as well that pushed output helps promote receptive words to develop into productive words. Empirical studies have been conducted. Ellis and He (1999) found learners with output practice improved significantly in both receptive and productive vocabulary (FAV in this case) learning. The experiment by Fuente and José (2002) shows that negotiation of input plus pushed output resulted in more L2 target words' production than negotiation of input without pushed output. The experiment by Arash (2016) reveals that when L2 learners are given chances to produce the target words, their performance of word production is better than the performance when they are not given the chance. Arash (2016) therefore concluded that pushed output can improve L2 word production.

It may be necessary to note that the pushed output in this study refers to the pushed "semantic" output, rather than pushed "formal" output, as output of forms does not do much for the words" semantic construction. Barcroft (2006) administered an experiment to check the effect of forced output of forms on vocabulary learning. In his study, subjects attempted to learn a group of L2 words by viewing word-picture pairs. In the process, the participants were asked to copy half of the target words, but not to do so for the other half of the target words. The productive vocabulary knowledge was tested after the treatment. Subjects were required to write down words after viewing relevant pictures. It is deemed in this study that the activity of picture-word writing to some extent assesses subjects' FAV, since the test does not provide any hint on the words' spelling or pronunciation to subjects. The subjects had to "freely and actively" produce the word when they saw the picture. Results of this study revealed that the no-copying group significantly outperformed the copying group in FAV learning. The implication of the study, according to Barcroft (2006), is that the forced output without access to meaning would have negative effects on vocabulary (FAV in this case) learning, as learners have to spare processing resource to encode forms of the words.

Although Krashen (1998), who proposed the Input Hypothesis, doubts the significance of output in second language acquisition (SLA), this study seems to support the opposite view that output does play a positive role in SLA, specifically in FAV acquisition in this case. When students try to create sentences with the target word, they are "pushing" themselves beyond their current level of word use, as they force themselves to use a word that they never used before. They tend to make more mental effort in this condition than when they solely receive input of the word from the teacher. This may be the reason why the pushed output activity can work effectively for FAV development.

All the effective learning strategies reported by the interviewees can be explained by theories of Depth of Processing, Task-induced Involvement. The Theory of Depth of Processing is proposed by Craik and Lockhart (1972). According to the theory, the depth at which a piece of information is 
processed is an important factor in memorization: the deeper the processing is, the better the memorization will be (Craik \& Lockhart, 1972). For example, trying to memorize a word out of context and trying to memorize a word in context may involve different depth of processing: memorizing the word in context involves more meaning analysis than memorizing it out of context, and therefore it may bring better results (Yue, 2008). The shallow depth of processing might primarily be on sensory levels, such as visual or acoustic processing; deeper processing might primarily be on meaning analysis and structure analysis (Craik \& Lockhart, 1972). The strategies of making sentences, referring to a dictionary, taking notes on word meanings, putting down example sentences, analysing the context, and collecting synonyms may all result in a deep processing on the target word. Therefore, these learning methods work effectively for FAV development.

Another theory is Task-induced Involvement Theory, proposed by Laufer and Hulstijn (2001). Laufer and Hulstijn (2001) hold that different tasks tend to elicit different amounts of cognitive involvement load. The cognitive involvement includes three aspects: need, search, and evaluation. Different tasks contain different loads of involvement in the three aspects, thus result in various acquisition results. For instance, in the study by Duan and Yan (2004), experimented words were presented to participants in different ways. The participants of Group 1 read an article with target words and then did multiple-choice tasks, in which correct meanings for the target words should be chosen. Each of the tasks had more than one correct answer. The participants of Group 2 read the same article with the target words, and then did multiple-choice tasks for correct word meanings as well, but each task had only one correct answer. Group 3 read the article with the target words, and the word meanings were given to them directly. The three tasks contained different levels of involvement. The first task elicited all the three involvements. There was "need" to seek the word meanings, "search" to look for the correct choices of word meanings, and "evaluation" to judge whether the choices were correct or not. The second task elicited all the three involvements as well, but the amount of "search" and "evaluation" was most likely smaller than that in the first task. It was because in the second task only one correct choice needed to be selected and evaluated. By contrast, in the first task two or more than two correct choices needed to be found, therefore it needed more effort in "search" and "evaluation". The study showed that the first task resulted in the best word acquisition outcome, the second task came next, and the third one resulted in the least acquisition. The study verified the Task-induced Involvement Theory.

In fact, the Theory of Depth of Processing and Task-induced Involvement are related to each other, as the Task-induced Involvement is developed on the basis of Theory of Depth of Processing (Yue, 2008). The weakness of the Theory of Depth of Processing is that the "depth" cannot be quantified and measured. By contrast, the Task-induced Involvement overcomes this weakness, as the theory makes the amount of involvement possible to be measured and evaluated by investigating whether the task contains "need", "search", and "evaluation". Therefore, the Task-induced Involvement makes relevant empirical studies feasible to be conducted (Yue, 2008).

The next series of questions aim to investigate teachers' guidance on FAV learning and the effective teaching strategies they adopted to assist students' FAV development. When being asked whether their teachers had told them the importance of FAV, all the interviewees answered yes. However, they recalled that only one teacher teaching them Intensive Reading in the third year did so. This indicates that many teachers may not be conscious of the significance of FAV; even if they have the consciousness, they may not take any action to help students improve FAV. The guidance that students can obtain from teachers, therefore, is limited. In addition, teachers may lack knowledge on how to help students effectively, as the literature review reflected that the relevant research is rather limited. This condition makes students unable to get adequate guidance from teachers.

The lack of strategy guidance can be evidenced from the interview. When the investigator asked 
the interviewees whether their teachers had given them suggestions on how to improve FAV, two of them reported no specific methods recommended by their teachers. Only one interviewee reflected that the Intensive Reading teacher suggested them to put down new words in notebooks, and to deliberately use them in writing. The teacher told them that this was a method used by one of her former students, who had good writing capability.

It was found that few teaching strategies had been adopted to enlarge students' FAV. However, the interviewees described some teaching strategies that aimed for other purposes but played a positive role in FAV acquisition. For instance, two interviewees recalled that some teachers often provided them with synonyms of the target words. For instance, one of them reflected that once in class when students were studying the words "strength" and "weakness", the teacher provided them synonyms of "advantage" and "disadvantage", and "merit" and "demerit". In this way, not only the target words were learned, their synonyms were learned as well.

One of the teachers took a step further. Instead of solely providing synonyms, the teacher conducted "negotiation" to students. According to Arash (2016), "negotiation" means to negotiate the meaning of the word, such as to clarify, confirm, or repeat the word meaning to students. The study by Arash (2016) shows that input of word meaning with negotiation leads to greater FAV gains than input of word meaning without negotiation. Another study testifies the positive effect of both negotiation and pushed output. The research by Teng (2015) shows that extensive reading with negotiation and pushed output activities prompt more FAV gains than solely extensive reading does. In this study, the interviewee said:

Maybe because the teacher majors in literature, she has a precise understanding of words. Most teachers would only provide us with a general explanation on a target word, or just give us a translation or an example sentence with it. But she would analyse why this word is used properly here, and why the word is a good choice. She often does so.

This method goes one step further than offering synonyms, translations, or examples, as it gives students detailed information on the words' connotations, and a deeper analysis on the words' context. In other words, it provides students with "negotiations" of the word. Negotiation helps students have a deeper processing on the word. Negotiation may help students set up semantic network in mental lexicon as well. When students encounter a proper circumstance, the word will be more easily reached and retrieved from their mental lexicon. This may be the reason why negotiation can help students in FAV development.

\section{Conclusion}

The interviews in this chapter obtain information in the four aspects proposed at the beginning of the study. The first aspect is students' consciousness to FAV in L2 study. It shows that students know FAV, and the awareness is most likely aroused by the difficulty they encounter in word production. They all have taken some effort trying to enlarge it in study.

The second aspect is on effective learning strategies students adopt for FAV development. It is reflected that students do take some measures trying to enlarge their FAV size. The strategies that they feel effective include making sentences with the word, taking notes of the word's meaning, putting down example sentences, attempting to use the word in proper context, and collecting synonyms. A problem was revealed from the interview. The number of strategies adopted is limited, the inadequacy in strategy use may be one factor for FAV stagnation.

The third aspect is teachers' guidance of FAV learning. Regrettably, the interview indicates that many teachers may not be aware of the significance of FAV; even if some of them know it, they fail to give adequate guidance to students on FAV learning. In the interview it was reflected that almost no teachers, except for one Intensive Reading teacher, had ever mentioned FAV to students. In 
addition, few suggestions had been given to the interviewees on how to enlarge FAV storage.

The fourth aspect is effective teaching strategies that may help students in FAV development. The interview shows that the guidance provided by teachers on FAV development is not adequate. However, some teaching methods were found by interviewees to be helpful to FAV development, although they were not adopted for this purpose. These methods include providing synonyms, negotiating word meanings, analysing contexts, arousing students' attention to target words, etc. Some effective teaching strategies overlap with students' learning strategies. Like the effectiveness of learning strategies, the effectiveness of these teaching strategies can be theoretically explained by the Depth of Processing Theory and Task-induced Involvement Theory.

Some problems are detected from the interview. The first problem is that students lack proper guidance in FAV development. The interview shows that many teachers almost never mention FAV in teaching, let alone provide students with instructions and suggestions on how to improve it. Moreover, few teaching strategies are adopted to help promote students' FAV development. However, it may be hasty to blame this neglect on teachers, as research in this field is rather limited, and it cannot give teachers enough guidance yet. Although researchers have detected the FAV threshold phenomenon in L2 study, there is a limited number of studies, especially empirical ones, on how to tackle this problem. Even if teachers feel the great necessity to help students enlarge their FAV, they can find little reference to give them valuable suggestions. Therefore, relevant research is in dire need. On the students' side, realizing the significance of FAV, they have to "grope" for effective learning methods by themselves. The effectiveness of their trials thus mostly depends on luck. Some strategies may turn out to be helpful, some may not; some may be helpful, but may only be helpful to a specific person, rather than having a universal value. The second problem is that although the interview shows that students know FAV, the number of strategies they use is rather limited.

Findings of the interview shed some light on ways to enlarge FAV. On the learning side, students not only need to know the significance of FAV, but also need to know useful strategies to tackle the problem. The interview shows that pushed-output activities, such as making sentences with the target word, may help. In addition, collecting synonyms, analysing context, taking notes of example sentences, paying extra attention to the target word may help as well. Continuous effort should be made, as achieving significant FAV growth may need a long process. On the teaching side, teachers should realize the significance of FAV in L2 study. They should remind students to keep paying attention to FAV development. They should give students suggestions and guidance on how to tackle the stagnation problem. Moreover, teachers should adopt effective teaching strategies to assist students. The interview shows that helpful teaching strategies include negotiation, context analysis, synonym collection, and drawing students' attention to target words. It can be seen that some of the effective teaching strategies overlap with the effective learning strategies.

However, it should be noted that the effectiveness of those strategies is based on the interviewees' subjective judgment, not evidenced by empirical studies yet. Effective learning and teaching strategies not only should be guided by experience and theories, but also need to be tested by empirical studies. Therefore, it is recommended that more empirical research be conducted to verify the effectiveness of these strategies. It is believed that with quantitative support the conclusion will be more convincing and instructive to FAV learning.

\section{Acknowledgement}

This article was written as part of the output of National social science fund project "Research on Feedback Mode of English Writing Formative Evaluation” (Project No.:14BYY083), the project "Characteristics of the Development in Advanced ESL Learners' Free Active Vocabulary 
Acquisition” funded by Shanxi Scholarship Council of China (Project No.:2014-067), and the project "Study on Effective Teaching Methods for L2 Productive Vocabulary", supported by Shanxi Social Science Council (Project No.:SSKLZDKT2012056).

\section{References}

[1] Laufer, B., \& Paribakht, T. S. (1998). The relationship between passive and active vocabularies: Effects of language learning context. Language Learning, 48(3), 365-389.

[2] Astika, G. G. (1993). Analytical assessments of foreign students' writing. RELC Journal: A Journal of Language Teaching and Research in Southeast Asia, 24(1), 61-72.

[3] Coady, J., Magoto, J., Hubbard, P., Graney, J., \& Mokhtari, K. (1993). High frequency vocabulary and reading proficiency in ESL readers. In T. Huckin, M. Haynes \& J. Coady (Eds.), Second language reading and vocabulary learning (pp. 217-228). Norwood, NJ: Ablex.

[4] Engber, C. A. (1995). The relationship of lexical proficiency to the quality of ESL compositions. Journal of Second Language Writing, 4(2), 139-155. doi: 10.1016/1060-3743(95)90004-7

[5] Laufer, B. (1994). The lexical profile of second language writing: Does it change over time? RELC Journal, 25(2), 21-33. doi: 10.1177/003368829402500202

[6] Yamamoto, Y. (2011). Bridging the gap between receptive and productive vocabulary size through extensive reading. Reading Matrix: An International Online Journal, 11(3), 226-242.

[7] Laufer, B. (1991). The development of L2 lexis in the expression of the advanced learner. The Modern Language Journal, 75(4), 440-448. doi: 10.2307/329493

[8] Gu, Q., \& Li, X. (2013). Study on productive vocabulary size of non-English major students. Journal of Tonghua Normal University, 34(3), 80-83.

[9] Huang, S. (2012). An evaluation of productive vocabulary capacity of English major students. Journal of Beijing Second Foreign Langue University, 212(12), 75-78.

[10] Lu, M. (2008). A study of productive vocabulary's development in breadth of knowledge. Foreign Language Learning Theory and Practice(2), 10-15.

[11] Tan, X. (2006). A study of Chinese English learners' productive vocabulary development. Foreign Language Teaching and Research, 38(3), 202-207.

[12] Wu, X., \& Chen, X. (2000). Development of lexical competence in the EFL classroom setting. Modern Foreign Languages, 23(4), 349-360.

[13] Zhao, Y. (2011). Fossilization in the output of high-frequency words from the "noticing" perspective. Foreign Language Research, 160(3), 100-102.

[14] Swain, M. (2000). The output hypothesis and beyond: Mediating acquisition through collaborative dialogue. In J. P. Lantolf (Ed.), Sociocultural theory and second language learning (pp. 97-114). Oxford: Oxford University Press.

[15] Schmitt, N., Schmitt, D., \& Clapham, C. (2001). Developing and exploring the behaviour of two new versions of the Vocabulary Levels Test. Language Testing, 18(1), 55-88.

[16] Swain, M. (1985). Communicative competence: Some roles of comprehensible input and comprehensible output in its development. In S. M. Gass \& C. G. Madden (Eds.), Input in second language acquisition (pp. 235-253). Rowley, MA: Newbury.

[17] Swain, M. (1995). Three function of output in second language learning: Principles and practice in applied linguistics. Oxford: Oxford University Press.

[18] Laufer, B. (1998). The development of passive and active vocabulary in a second language: Same or different? Applied Linguistics, 19(2), 255-271. doi: 10.1093/applin/19.2.255

[19] Henriksen, B. (1999). Three dimensions of vocabulary development. Studies in Second Language Acquisition, 21(2), 303-317.

[20] Ellis, R., \& He, X. (1999). The roles of modified input and output in the incidental acquisition of word meanings. Studies in Second Language Acquisition, 21(2), 285-301.

[21] Fuente, D. L., \& José, M. (2002). Negotiation and oral acquisition of L2 vocabulary: The roles of input and output in the receptive and productive acquisition of words. Studies in Second Language Acquisition, 24(1), 81-112.

[22] Arash, A. (2016). Effects of non-negotiated pre-modified input, negotiation of input without output, and negotiation of input plus pushed output on EFL learners' vocabulary learning. Journal of Language Teaching and Research, 7(4), 773-779. doi: 10.17507/jltr.0704.19

[23] Barcroft, J. (2006). Can writing a new word detract from learning it? More negative effects of forced output during vocabulary learning. Second Language Research, 22(4), 487-497.

[24] Krashen, S. (1998). Comprehensible output? System, 26(2), 175-182.

[25] Craik, F. I. M., \& Lockhart, R. S. (1972). Levels of processing: A framework for memory research. Journal of 
Verbal Learning and Verbal Behavior, 11(6), 671-684. doi: 10.1016/s0022-5371(72)80001-x

[26] Yue, Y. (2008). Research on L2 incidental vocabulary acquisition in China: Review and inspiration. Journal of Taiyuan Normal University (Social Science Edition), 7(2), 165-167.

[27] Yue, Y. (2018). Breaking through the threshold in L2 free active vocabulary acquisition. PhD Thesis, University of Tasmania

[28] Yue, Y. (2019). The threshold phenomenon in L2 free activev vocabulary acquisition: reasons and solutions (in press). Jilin Universitiy Press, Jilin, China

[29] Laufer, B., \& Hulstijn, J. (2001). Incidental vocabulary acquisition in a second language: The construct of taskinduced involvement. Applied Linguistics, 22(1), 1-26.

[30] Duan, S., \& Yan, C. (2004). Effects of multiple-choice annotation on ESL incidental vocabulary acquisition. Foreign Language Teaching and Research, 36(3), 213-218.

[31] Teng, F. (2015). The effectiveness of extensive reading on EFL learners' vocabulary learning: Incidental versus intentional learning. Brazilian English Language Teaching Journal, 6(1), 82-96. 